\title{
PD-L1 expression can be regarded as prognostic factor for survival of non-small cell lung cancer patients after chemoradiotherapy
}

\author{
M. VRANKAR ${ }^{1}$, M. ZWITTER ${ }^{1}$, I. KERN ${ }^{2}$, K. STANIC ${ }^{1, *}$ \\ ${ }^{1}$ Department of Radiotherapy, Institute of Oncology, Ljubljana, Slovenia; ${ }^{2}$ Laboratory for Cytology and Pathology, University Clinic Golnik, \\ Golnik, Slovenia \\ ${ }^{*}$ Correspondence: kstanic@onko-i.si
}

Received February 6, 2017 / Accepted May 9, 2017

\begin{abstract}
Inoperable locally advanced non-small cell lung cancer (LA NSCLC) is treated with concurrent or sequential chemotherapy (ChT) and radiation therapy (RT). Survival rates with this treatment remains poor, reported 5-year survival is about $15 \%$. New treatment strategies, including immunotherapy with programmed death ligand-1 (PD-L1) check point inhibitors are being investigated. The clinical significance of PD-L1 expression in tumor samples from patients with inoperable LA NSCLC who underwent concurrent chemoradiotherapy (CRT) in our institution between 2005 and 2010 was evaluated. The expression of PD-L1 was correlated with clinical and pathological parameters and outcome of treatment. We analysed 107 patients treated with concurrent CRT. Only 43 patients ( 36 males and 7 females) had sufficient tissue for immunohistochemical (IHC) staining. PD-L1 expression was demonstrated in 7 tumors. No statistical significant differences in patient characteristics, including age, smoking status and gender, were found according to the PD-L1 expression. After a median follow up of 103.6 months, median progression free survival (PFS) was 19.9 months in patients without and 10.1 months in patients with PD-L1 expression ( $\mathrm{p}=0.006)$. Median overall survival (OS) was 28.4 and 12.1 months for PD-L1 negative and PD-L1 positive patients, respectively $(\mathrm{p}=0.012)$.

In conclusions, PD-L1 expression was negative prognostic factor for PFS and OS after concurrent CRT in LA NSCLC. As only small number of patients had enough tissue for the IHC testing, no firm conclusions could be made and further investigation is warranted.
\end{abstract}

Key words: locally advanced non-small cell lung cancer, PD-L1 expression, concurrent chemoradiotherapy, radiotherapy

Non-small cell lung cancer (NSCLC) accounts for approximately $85 \%$ of all primary lung cancers, of whom about one fourth have locally advanced disease [1]. The standard treatment for patients with surgically inoperable, locally advanced NSCLC includes concurrent RT and ChT [2]. Long term survival rates with these approaches remains only in the order of $15 \%$ [2]. Novel treatment strategies, including immunotherapy, are under investigation to improve patients' prognosis. The PD-L1 has been recently suggested to play a crucial role in the immune evasion of tumors from host immune system.

Expression of PD-L1 in tumor assists in immune tolerance and evasion of host immunity by down regulating antitumor T-cell response. There are data suggesting that PD-L1 expression is predictive of tumor response to blockade of the PD-1/PD-L1 pathway in different solid tumors including NSCLC, but little is known about the association of PD-L1 expression and clinicopathological variables and outcomes of patients with NSCLC.

In this analysis, we evaluated the clinical and prognostic significance of PD-L1 expression in patients with locally advanced inoperable NSCLC.

\section{Patients and methods}

Patients characteristics. All patients included in the retrospective analysis were treated with curative intent in our institution from September 2005 to November 2010. Treatment consisted of three cycles of induction ChT with gemcitabine and cisplatin, followed by RT concurrent with ChT. All patients underwent three-dimensional CT-based conformal RT with a linear accelerator photon beam of $5-10 \mathrm{MV}$ with a total dose of $60-66 \mathrm{~Gy}$ in 2 Gy fractions 5 
times weekly. Concurrently, patients were treated with two cycles of cisplatin and etoposide [3].

Information was collected on patient demographics, pathological features, TNM stage, overall response rate (ORR), PFS and OS. Staging was undertaken according to the $7^{\text {th }}$ edition AJCC tumor, node and metastasis (TNM) classification [4]. The ORR was evaluated by two independent experienced radiologists 5 month after completion of treatment according to Response Evaluation Criteria in Solid Tumor (RECIST) criteria version 1.1. Toxicities were assessed according to Common Terminology Criteria for Adverse Events (CTCAE) version 3.0 [5].

Tumor tissue and immunohistochemistry. Archived tumor tissue samples were collected from patients with histologically confirmed diagnosis of NSCLC in a diagnostic work-up before any tumor directed treatment. Tumor tissue was formalin fixed and paraffin embedded (FFPE). At least 100 viable tumor cells were regarded as a sufficient tumor content to perform immunohistochemistry (IHC).

Fresh cut FFPE tissue sections were stained for PD-L1. A rabbit monoclonal antibody was used (clone SP142; Ventana, Roche, USA) on an automated staining platform (BenchMark XT, Ventana, Roche, USA). An OptiView DAB Detection Kit with Amplification Kit (Ventana, Roche, USA) was used according to the manufacturer's instructions for visualization. PD-L1 expression was evaluated on tumor cells as well as tumor infiltrating immune cells. PD-L1 expression was confirmed when tumor cell membrane or tumor infiltrating cells with cytoplasmic positive reaction at any intensity was detected. Staining threshold for PD-L1 positivity was set arbitrary at 5\% (percentage of cells stained positive) or higher in either tumor cells or tumor infiltrating immune cells.

Statistical analysis. OS and PFS curves were estimated using Kaplan-Meier method. Pearson's chi-squared test or Fisher's exact test was used to assess correlations between different immunoreactivity and clinicopathological variables. PFS and OS of patients with positive or negative immunostaining were compared using the log-rank test. The Cox proportional hazards model was used to assess the association between OS, PDL-1 status and patient and treatment characteristics. Results with values of $p<0.2$ in univariate analysis were calculated in multivariate analysis.

PFS was defined as the time from the beginning of treatment to disease progression or death. OS was calculated as the time from the start of the treatment to death from any cause. Censoring was defined as the time from the beginning of treatment to the last contact with the patient and for alive patients, as the time from the beginning of treatment to the end of follow-up (August 2016). The statistical analyses were done using SPSS -21 (IBM Corporation, Armonk, NY, USA). All tests were two tailed. A p-value less than 0.05 was considered statistically significant. The study was approved by the National Committee for Medical Ethics (KME 109/04/05). All patients signed informed consent to participate in the study.

\section{Results}

Patients characteristics. Among one hundred seven patients, a total of 43 had sufficient tissue for IHC staining. Most of them were small biopsies (37 bronchial biopsies, 3 transbronchial biopsies, 1 CT-giuded lung core biopsy, 1 lung wedge biopsy, 1 lymph node biopsy). Samples were collected and analyzed from 36 males and 7 females. The PD-L1 expression was demonstrated in 7 tumors, in 6 males and 1 female. All positive cases had positivity observed in tumor cells (10-80\%), only in a case of lung wedge biopsy positivity for tumor infiltrating immune cells was detected. PD-L1 expression according to patient demographics and disease characteristics are presented in Table 1. All patients had surgically inoperable tumor, 21 patients (49\%) were in stage IIIA and 22 patients in stage IIIB (51\%). Thirty nine patients had no previous treatment, 4 patients were referred for CRT after explorative thoracotomy and 1 patient had a local recurrence 1 year after surgery, all in the group with no PD-L1 expression. The most predominant histological subtype was squamous cell carcinoma (74\%), followed by adenocarcinoma (16\%). No statistical significant differences in patient characteristics were found according to the PD-L1 expression.

The treatment delivery for 43 patients is listed in Table 2. The dose intensity of induction chemotherapy, measured with percentage of patients receiving more than $80 \%$ of scheduled dose was $63.9 \%$ for cisplatin and $75 \%$ for gemcitabine in PD-L1 negative patients and $71.4 \%$ and $100 \%$ in patients with PD-L1 expression. Among PD-L1 negative patients, radical RT with doses of $>60$ Gy was completed in $55.6 \%$ and in $16.7 \%$ of patients positive for PD-L1 expression ( $\mathrm{p}=0.078$ ).

The dose intensity of concurrent ChT was $27.8 \%$ for cisplatin and $69.4 \%$ for etoposide in PD-L1 negative patients and

Table 1. Characteristics of patients.

\begin{tabular}{|c|c|c|c|c|}
\hline & & $\begin{array}{c}\text { PD-L1 } \\
\text { negative } \\
(\mathrm{n}=36)\end{array}$ & $\begin{array}{c}\text { PD-L1 } \\
\text { expression } \\
(\mathrm{n}=7)\end{array}$ & p-value \\
\hline \multirow{2}{*}{$\begin{array}{l}\text { Gender, } \\
\text { n (\%) }\end{array}$} & male & $30(83.3 \%)$ & $6(85.7 \%)$ & \multirow{2}{*}{0.876} \\
\hline & female & $6(16.7 \%)$ & $1(14.3 \%)$ & \\
\hline \multirow{2}{*}{$\begin{array}{l}\text { Age } \\
\text { (years) }\end{array}$} & median & 57.9 & 59.3 & \multirow{2}{*}{0.631} \\
\hline & range & $42-77$ & $54-64$ & \\
\hline \multirow{2}{*}{$\begin{array}{l}\text { Stage group, } \\
\mathrm{n}(\%)\end{array}$} & IIIA & $19(52.8 \%)$ & $2(28.6 \%)$ & \multirow{2}{*}{0.241} \\
\hline & IIIB & $17(47.2 \%)$ & $5(71.4 \%)$ & \\
\hline \multirow{2}{*}{ Histology } & $\begin{array}{l}\text { Squamous-cell } \\
\text { carcinoma }\end{array}$ & $26(72.2 \%)$ & $6(85.7 \%)$ & \multirow{2}{*}{0.313} \\
\hline & $\begin{array}{l}\text { adenocarcinoma } \\
\text { \& other }\end{array}$ & $10(27.8 \%)$ & $1(14.3 \%)$ & \\
\hline \multirow{2}{*}{$\begin{array}{l}\text { Smoking } \\
\text { history }\end{array}$} & Never or ex smoker & $18(50 \%)$ & $5(71.4 \%)$ & \multirow[b]{2}{*}{0.298} \\
\hline & $\begin{array}{l}\text { Current smoker at } \\
\text { the time of diagnosis }\end{array}$ & $18(50 \%)$ & $2(28.6 \%)$ & \\
\hline
\end{tabular}

Abbreviations: $\mathrm{PD}-\mathrm{L} 1=$ programmed death ligand $-1, \mathrm{n}=$ number 

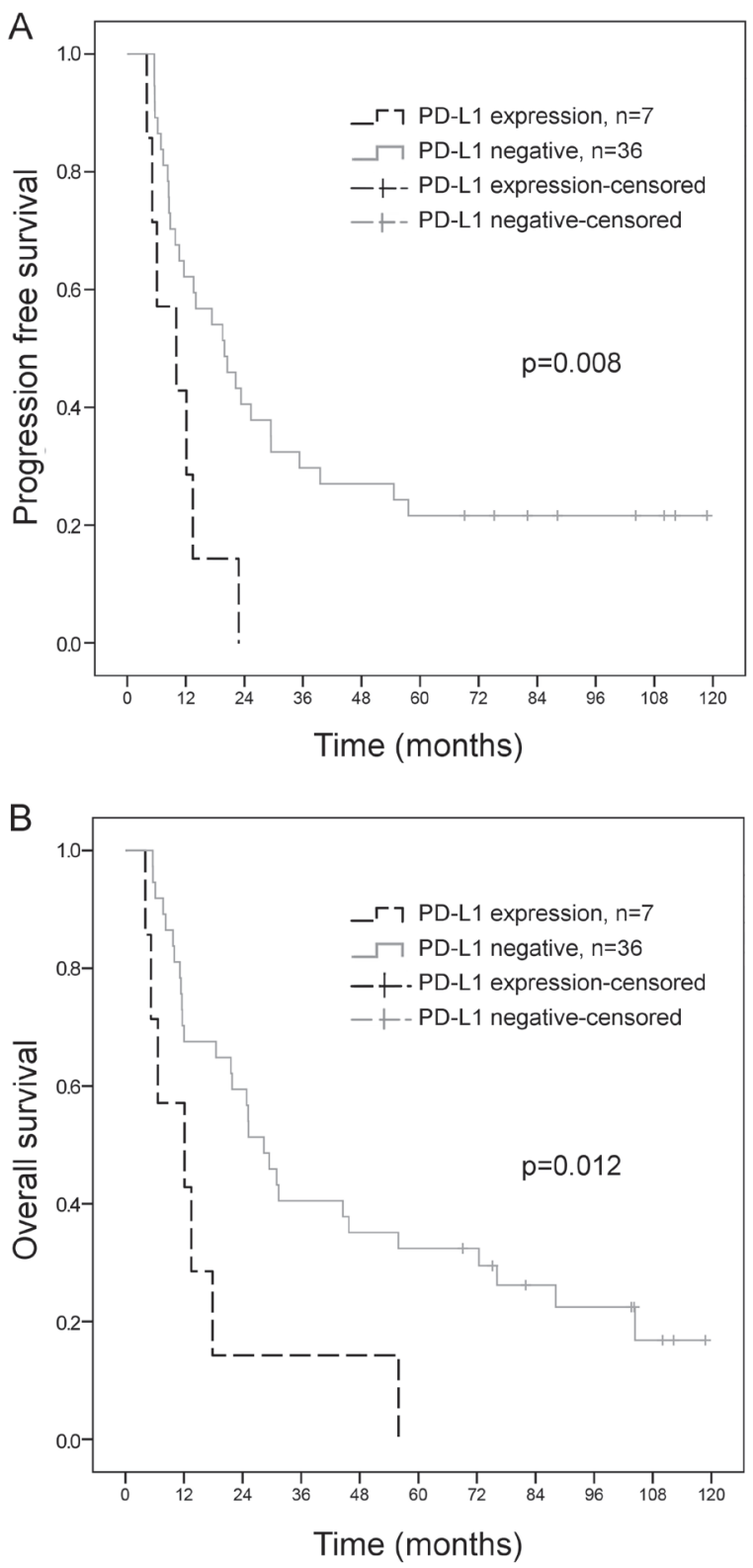

Figure 1. (A) Progression free survival with respect to expression of PD-L1. (7 patients had expression of PD-L1, 36 were PD-L1 negative, $\mathrm{p}=0.008$ ). (B) Overall survival with respect to expression of PD-L1 (7 patients had expression of PD-L1, 36 were PD-L1 negative, $p=0.012$ )

$14.3 \%$ for cisplatin and $14.3 \%$ for etoposide in patients with PD-L1 expression. The difference was not statistically significant for cisplatin $(\mathrm{p}=0.454)$ but was for etoposide $(\mathrm{p}=0.006)$. One PD-L1 negative patient and one with PD-L1 expression received no concurrent $\mathrm{ChT}$ due to hematological toxicity and esophagitis.

Response and survival. Five months after completion of treatment, 33 patients were evaluable for response according to RECIST criteria (Table 3). ORR was observed in 23 patients (79.3\%) with PD-L1 negative tumors and in 2 patients (50\%)
Table 2. Treatment delivery.

\begin{tabular}{|c|c|c|c|c|}
\hline & & $\begin{array}{c}\text { PD-L1 } \\
\text { negative } \\
(\mathrm{n}=36)\end{array}$ & $\begin{array}{c}\text { PD-L1 } \\
\text { expression } \\
(\mathrm{n}=7)\end{array}$ & p-value \\
\hline \multirow{2}{*}{$\begin{array}{l}\text { Induction } \\
\text { chemotherapy }\end{array}$} & $\begin{array}{l}\geq 80 \% \text { of scheduled } \\
\text { cisplatin (\% of pts) }\end{array}$ & 63.9 & 71.4 & 0.702 \\
\hline & $\begin{array}{l}\geq 80 \% \text { of scheduled } \\
\text { gem (\% of pts) }\end{array}$ & 75 & 100 & 0.137 \\
\hline \multirow{2}{*}{$\begin{array}{l}\text { Concomitant } \\
\text { chemotherapy }\end{array}$} & $\begin{array}{l}\geq 80 \% \text { of scheduled } \\
\text { cisplatin (\% of pts) }\end{array}$ & 27.8 & 14.3 & 0.454 \\
\hline & $\begin{array}{l}\geq 80 \% \text { of scheduled } \\
\text { etoposide (\% of pts) }\end{array}$ & 69.4 & 14.3 & 0.006 \\
\hline \multirow{2}{*}{ RT doses } & $\begin{array}{l}\text { RT dose }>60 \text { Gy } \\
\text { (\% of pts) }\end{array}$ & 55.6 & 16.7 & \multirow{2}{*}{0.078} \\
\hline & $\begin{array}{l}\text { RT dose } \leq 60 \text { Gy } \\
\text { (\% of pts) }\end{array}$ & 44.4 & 83.3 & \\
\hline
\end{tabular}

Abbreviations: $\mathrm{PD}-\mathrm{L} 1=$ programmed death ligand $-1, \mathrm{RT}=$ radiation therapy, $\mathrm{n}=$ number, gem=gemcitabine, $\mathrm{pts}=$ patients

Table 3. Summary of response rates, PFS and OS by expression of PD-L1.

\begin{tabular}{|c|c|c|c|c|}
\hline & & $\begin{array}{c}\text { PD-L1 } \\
\text { negative }\end{array}$ & $\begin{array}{c}\text { PD-L1 } \\
\text { expression }\end{array}$ & p-value \\
\hline \multirow{3}{*}{$\begin{array}{l}\text { Objective response } \\
\text { rate after treatment } \\
\text { - RECIST }\end{array}$} & ORR & $23(79.3 \%)$ & $2(50 \%)$ & \multirow[b]{2}{*}{0.200} \\
\hline & $\mathrm{PD}$ & $6(20.7 \%)$ & $2(50 \%)$ & \\
\hline & $\begin{array}{l}\mathrm{V}\left(\mathrm{cm}^{3}\right) \text { (median) } \\
\text { before ChT }\end{array}$ & 210 & 189 & 0.841 \\
\hline \multirow{3}{*}{$\begin{array}{l}\text { Response rate } \\
\text { after induction } \\
\text { CT-volumetric } \\
\text { results }\end{array}$} & $\begin{array}{l}\mathrm{V}\left(\mathrm{cm}^{3}\right)(\text { median}) \\
\text { after ChT }\end{array}$ & 85 & 70 & 0.815 \\
\hline & $\begin{array}{l}\% \text { of volume } \\
\text { decrease }\end{array}$ & 58.3 & 60.5 & 0.817 \\
\hline & (median) & & & \\
\hline \multicolumn{2}{|l|}{ Median PFS (month) } & 19.9 & 10.1 & 0.008 \\
\hline \multicolumn{2}{|l|}{ Median OS (month) } & 28.4 & 12.1 & 0.012 \\
\hline \multicolumn{2}{|l|}{ 1-year OS (\%) } & 70.3 & 42.9 & \\
\hline \multicolumn{2}{|l|}{ 3-year OS (\%) } & 40.5 & 14.3 & \\
\hline \multicolumn{2}{|l|}{ 5-year OS (\%) } & 32.4 & 0 & \\
\hline
\end{tabular}

Abbreviations: $\mathrm{ORR}=$ overall response rate, $\mathrm{PD}=$ progressive disease, $\mathrm{PFS}=$ progression free survival, $\mathrm{OS}=$ overall survival, $\mathrm{V}=$ volume, $\mathrm{PD}-\mathrm{L} 1=$ programmed death ligand $-1, \mathrm{ChT}=$ chemotherapy, RECIST $=$ Response Evaluation Criteria in Solid Tumor

with PD-L1 expression. Complete response was observed in $10(33.3 \%)$ patients with PD-L1 negative tumors and in 2 (50\%) patients with PD-L1 expression. No statistical significant differences were found in ORR 5 months after completion of treatment, volumetric measurements and histology according to the PD-L1 expression. Median follow-up time of surviving patients was 103.6 months (range 69.1-118.8 months). Median PFS was 19.9 months in PD-L1 negative patients and 10.1 months in patients with PD-L1 expression $(\mathrm{p}=0.008$, Figure $1 \mathrm{~A})$. Median OS in PD-L1 negative patients was 28.4 months compared to 12.1 months in patients with PD-L1 expression ( $\mathrm{p}=0.012$, Figure $1 \mathrm{~B})$. The OS rates at 
1, 3 and 5 years were $70.3 \%, 40.5 \%$ and $32.4 \%$ for PD-L1 negative patients and $42.9 \%, 14.3 \%$ and $0 \%$ for patients with PD-L1 expression, respectively. At the time of last evaluation in August 2016, 8 patients were alive without progressive disease, all PD-L1 negative.

In univariate analysis, PDL-1 expression (HR 2.84; CI=1.2 -6.69 ), stage IIIB (HR 2.32; CI=1.14-4.72) and dose of RT $\leq 60$ Gy (HR 0.55; CI=0.27-1.10) were significant factors for worse survival. In multivariate analysis only higher stage (HR 2.36) and PD-L1 expression (HR 2.84) were independent prognostic factors for worse survival (Table 4).

\section{Discussion}

We assessed the potential role of PD-L1 expression on PFS and OS in patients with inoperable stage IIIA and IIIB NSCLC treated with combined CRT. The results of our analysis show significant differences in PFS and OS according to the expression of PD-L1 suggesting poor prognosis in NSCLC patients with PD-L1 expression. We found no statistical significant relationship between PD-L1 expression and gender, age, stage, histology and smoking history.

Most of published retrospective studies on the clinicopathological characteristics of the tumors expressing PD-L1 in NSCLC included patients who underwent surgically resection [6-14]. The results of these studies are inconsistent. Two recent meta-analysis showed that high PD-L1 expression correlated with poor prognosis in patients with early stage
NSCLC $[15,16]$. They included only one study in Western populations, all others were completed in Asian populations $[6,8-10,12,14]$. In the study with Western populations, Velcheti et al. found that PD-L1 expression was associated with better outcome of patients with surgically resected early stage NSCLC [12]. Additional information from Western populations is available from 3 other studies. In the study performed by Cooper et al. patients with high PD-L1 expression (using $>50 \%$ staining to determine positivity) had significantly longer overall survival compared to those with low PD-L1 expression and this prognostic association was observed in squamous cell carcinomas and non-adenocarcinomas but not in adenocarcinomas [13]. High PD-L1 expression was also associated with younger patient age and high tumor grade. In the study of Schmidt et al., PD-L1 expression on tumor cells was associated with improved overall survival in squamous cell carcinomas, adjuvant therapy, greater tumor size and positive lymph node status [17]. On the contrary, Sorenson et al. found no association between PD-L1 expression and overall survival in a study of patients with advanced stage IV NSCLC treated with ChT [18].

To our knowledge, we are among the first to present data of clinicopathological characteristics and prognostic value of PD-L1 expression for patients with locally advanced inoperable stage III NSCLC who were treated with combined CRT. In the report of Adam et al. prognostic value of PDL1 expression in stage III NSCLC treated by CRT was assessed [19]. The results were in concordance with our observa-

Table 4. Univariate and multivariate analysis of prognostic factors for survival

\begin{tabular}{|c|c|c|c|c|c|c|}
\hline & \multicolumn{3}{|c|}{ Univariate analysis } & \multicolumn{3}{|c|}{ Multivariate analysis } \\
\hline & p-value & HR & CI & p-value & HR & CI \\
\hline $\begin{array}{l}\text { Age } \\
0 \leq 58,1>58\end{array}$ & 0.45 & 0.758 & $0.372-1.547$ & & & \\
\hline $\begin{array}{l}\text { Gender } \\
0=\text { male, } 1=\text { female }\end{array}$ & 0.71 & 0.832 & $0.321-2.158$ & & & \\
\hline $\begin{array}{l}\text { Stage } \\
0=\text { IIIA, } 1=\text { IIIB }\end{array}$ & 0.02 & 2.327 & $1.147-4.721$ & 0.022 & 2.365 & $1.132-4.939$ \\
\hline $\begin{array}{l}\text { Lymphocyte decrease } \\
0 \leq 77 \%, 1>77 \%\end{array}$ & 0.46 & 0.926 & $0.464-1.846$ & & & \\
\hline $\begin{array}{l}\text { RT dose } \\
0 \leq 60 \mathrm{~Gy}, 1>60 \mathrm{~Gy}\end{array}$ & 0.09 & 0.550 & $0.274-1.105$ & 0.77 & 0.889 & $0.394-2.004$ \\
\hline $\begin{array}{l}\text { Dose of etoposide } \% \text { mean } \\
0 \leq 74,1>74 \%\end{array}$ & 0.23 & 0.650 & $0.327-1.304$ & & & \\
\hline $\begin{array}{l}\text { Dose of cisplatin } \% \text { mean } \\
0 \leq 60,1>60 \%\end{array}$ & 0.40 & 0.747 & $0.376-1.482$ & & & \\
\hline $\begin{array}{l}\text { Smoking status } \\
0=\text { no or ex smoker, } 1=\text { smoker }\end{array}$ & 0.21 & 1.713 & $0.742-3.951$ & & & \\
\hline $\begin{array}{l}\text { Histology } \\
0=\text { squamous cell, } 1=\text { non-squamous cell }\end{array}$ & 0.64 & 1.206 & $0.556-2.615$ & & & \\
\hline $\begin{array}{l}\text { PD-L1 } \\
0=\text { negative, } 1=\text { positive }\end{array}$ & 0.02 & 2.843 & $1.207-6.699$ & 0.039 & 2.844 & $1.055-7.669$ \\
\hline
\end{tabular}


tion, PD-L1 positivity was associated with a poor survival in stage III NSCLC patients treated by definitive CRT. Median OS was 1.1 year in PD-L1 positive and 2.0 years in PD-L1 negative patients $(p=0.01)$, which is comparable with our results, 1 year in PD-L1 positive and 2.4 years in PD-L1 negative $(\mathrm{p}=0.012)$.

In the retrospective study of Tokito et al., analysis of 74 patients with stage III NSCLC treated with combined CRT demonstrated PD-L1 expression $(\geq 5 \%)$ in over $70 \%$ of patients, much higher than in our study. Primary aim of their study was to investigate the predictive relevance of PD-L1 expression and CD8+ tumour-infiltrating lymphocytes (TILs) density. While CD8+ TIL density was an independent and significant predictive factor for progression-free survival (PFS) and OS, for PD-L1 expression they only found a trend for poor survival [20].

RT has traditionally been used primarily as a method of local treatment on the basis that rapidly proliferating cancer cells are more sensitive to DNA damage induced by radiation than normal tissue. But $\mathrm{RT}$ is also thought to act as a kind of in situ "tumor vaccine" that prime an adaptive immune system $[21,22]$. Several studies have shown that there are various mechanisms by which RT could stimulate the immune system. One impact of radiation damage to tumors is the exposure of a large amount of tumor antigens $[23,24]$. The increased release of tumor-associated antigens provides its uptake by circulating dendritic cells and other antigen-presenting cells which result in the tumor-specific immune attack. In addition to release of the tumor-associated antigens, RT also creates an inflammatory milieu by inducing the release of several pro-inflammatory cytokines, including IL-1 $\beta$ and TNF- $\alpha$ [25]. It is likely that at least a proportion of the cancer cells within a tumor will die an immunogenic cell death when radiation is used at therapeutic doses [26]. In addition to local effect of RT on immune response, experimental data have provided sufficient evidence that some of the effects of irradiation contribute to systemic antitumor immunity [21, 27-29].

The clinical observation that best demonstrates the induction of systemic antitumor immunity by RT is the abscopal effect, the tumor response in a metastasis outside the irradiated field after irradiation of primary tumor or other metastatic site $[28,30]$. However, abscopal effects are rare as tumors have an escape mechanisms that can decrease lymphocytic activity [22]. One of the escape mechanisms is PD-1/PD-L1 pathway that acts as a major immunosuppressive pathway by which tumors suppress lymphocyte function within the tumor microenvironment. Our observation of significantly lower PFS and OS in patient with PD-L1 expression on tumor cells could be partly clarified by suppression of antitumor immunity due to the activated PD-1/ PD-L1 pathway. External beam RT concurrently with ChT is conventionally administered in fractionated doses of 1.8 to 2.0 Gy per fraction. This traditional low dose per fraction not seems to adequately trigger optimal immune response due to prolonged action of irradiation on $\mathrm{T}$ cells in the tumor. There are some suggestions that hypofractionation, on the other hand, has more effect on immunity [31]. However, it is unclear what optimal dose and fractionation schedule would contribute to systemic antitumor immunity most.

PD-L1 expression is predictive of tumor response to blockade of the PD 1/PD-L1 pathway in different solid tumors including non-squamous NSCLC. Blockade of immuneinhibitory PD1/PD-L1 pathway is an effective strategy for activating antitumor immunity [32]. Furthermore, substantial preclinical and early clinical studies have demonstrated that localized treatment of tumors with RT acts synergistically with immunotherapy to enhance antitumor immune responses [33]. RT also increase tumor expression of PD-L1, and combined RT and anti PD-1-pathway immunotherapy results in synergistic suppression of tumor-infiltrating myeloid-derived suppressor cells thereby promoting antitumor immunity $[34,35]$. However, radiation dose, fractionation schedules and the optimal timing of immunotherapy for optimal synergy between radiotherapy and immunotherapy are not well defined.

Most studies have used subjective visual PD-L1 levels estimation as indicator of positivity, most commonly the value of $5 \%$ of membrane-positive tumor cells has been used us a cutoff for tumor positivity due to association with clinical response to anti-PD-L1 therapy $[36,37]$. Using a threshold of $5 \%$ in cell staining we found PD-L1 expression in $15.9 \%$ patients. Our proportion of patients with PD-L1 expression is among the lowest in the literature. Velcheti et al. found PD-L1 expression in 36\% of patients with NSCLC of all stages in Greek cohort and in 25\% in Yale cohort [12]. Cooper et al. found PD-L1 expression in $20.1 \%$ of early stage NSCLC and Boland et al. in $19.6 \%$ of surgically treated squamous cell carcinoma $[7,38]$. Most other studies analyzing PD-L1 expression in Asian population report PD-L1 expression between $39.9 \%$ and $57.5 \%$ [8, 10]. Other studies used other methodologies for positive PD-L1 expression and different thresholds so the comparison is not accurate. Furthermore, different studies have analyzed the data of patients who differ in demographic characteristics, histological type of cancer, and race. In our series of patients with NSCLC the most common histological type was squamous cell carcinoma with $74 \%$ of patients, higher than usually present in the population of NSCLC. Possible explanation is central position of squamous cell carcinomas in bronchial tree, therefore in those cases there was enough pathologic material for molecular testing. Due to the heterogeneity of the tumors, tumor specimens from small biopsies also have lower proportion of cells with PD-L1 expression within the sample [39].

Major weakness of our study is the small number of patients analyzed due to the lack of tumor samples, although we included all patients with locally advanced inoperable stage III NSCLC that were treated in our institution between September 2005 and November 2010 with radical intent. The proportion of patients with LA NSCLC is about $30 \%$, but 
only a small proportion of these patients withstand intensive combined therapy due to comorbidity, age or low PS.

In the conclusion, our retrospective analysis assessed the clinical significance of PD-L1 expression in patients with locally advanced NSCLC. Patients with PD-L1 expression had shorter PFS and OS after concurrent CRT. Stage IIIB and PD-L1 expression were independent prognostic factors for worse survival. Unfortunately, the number of patients who had tissue available for the IHC testing was not big enough for firm conclusions; therefore further clinical investigation is warranted. Since the blockade of PD1/PD-L1 pathway is an effective strategy for activating antitumor immunity, the application of radiotherapy in combination with immunotherapy opens new avenues of investigation in patients with NSCLC and several ongoing trials are currently evaluating the impact of immune checkpoint inhibitors following concurrent CRT.

\section{References}

[1] Cancer in Slovenia 2013. Ljubljana: Institute of Oncology Ljubljana, Epidemiology and Cancer Registry, Cancer Registry of Republic of Slovenia, 2016. https://www.onko-i.si/eng/ crs/, as accessed on February, 2017.

[2] AUPÉRIN A, LE PÉCHOUX C, ROLLAND E, CURRAN WJ, FURUSE K et al. Meta-analysis of concomitant versus sequential radiochemotherapy in locally advanced nonsmall-cell lung cancer. J Clin Oncol 2010; 28: 2181-2190. doi: $\underline{10.1200 / \mathrm{JCO} .2009 .26 .2543}$

[3] VRANKAR M, ZWITTER M, BAVCAR T, MILIC A, KOVAC V. Induction gemcitabine in standard dose or prolonged low-dose with cisplatin followed by concurrent radiochemotherapy in locally advanced non-small cell lung cancer: a randomized phase II clinical trial. Radiol Oncol 2014; 48: 369-380. doi: 10.2478/raon-2014-0026

[4] UICC International Union Against Cancer. Lung cancer. pp 138-146. In: LH. Sobin, MK. Gospodarowicz, C. Wittekind (Eds.). TNM classification of malignant tumors, 7th edition. Chichester: Wiley-Blackwell, 2009, p 330. ISBN: 978-1-44433241-4

[5] Common Terminology Criteria for Adverse Events v3.0 (CTCAE). Available at http://ctep.cancer.gov/protocolDevelopment/electronic applications/docs/ctcaev3.pdf

[6] AZUMA K, OTA K, KAWAHARA A, HATTORI S, IWAMA E et al. Association of PD-L1 overexpression with activating EGFR mutations in surgically resected nonsmall-cell lung cancer. Ann Oncol 2014; 25: 1935-1940. doi: 10.1093/ annonc/mdu242

[7] BOLAND JM, KWON ED, HARRINGTON SM, WAMPFLER JA, TANG $\mathrm{H}$ et al. Tumor B7-H1 and B7-H3 expression in squamous cell carcinoma of the lung. Clin Lung Cancer 2013; 14: 157-163. doi: 10.1016/j.cllc.2012.05.006

[8] CHEN YB, MU CY, HUANG JA. Clinical significance of programmed death-1 ligand-1 expression in patients with non-small cell lung cancer: a 5-year-follow-up study. Tumori 2012; 98: 751-755. doi: 10.1700/1217.13499
[9] MU CY, HUANG JA, CHEN Y, CHEN C, ZHANG XG. High expression of PD-L1 in lung cancer may contribute to poor prognosis and tumor cells immune escape through suppressing tumor infiltrating dendritic cells maturation. Med Oncol 2011; 28: 682-688. doi: 10.1007/s12032-010-9515-2

[10] YANG CY, LIN MW, CHANG YL, WU CT, YANG PC. Programmed cell death-ligand 1 expression in surgically resected stage I pulmonary adenocarcinoma and its correlation with driver mutations and clinical outcomes. Eur J Cancer 2014; 50: 1361-1369. doi: 10.1016/j.ejca.2014.01.018

[11] KONISHI J, YAMAZAKI K, AZUMA M, KINOSHITA I, DOSAKA-AKITA $\mathrm{H}$ et al. B7-H1 expression on non-small cell lung cancer cells and its relationship with tumor-infiltrating lymphocytes and their PD-1 expression. Clin Cancer Res 2004; 10: 5094-5100. doi: 10.1158/1078-0432.CCR-04-0428

[12] VELCHETI V, SCHALPER KA, CARVAJAL DE, ANAGNOSTOU VK, SYRIGOS KN et al. Programmed death ligand-1 expression in non-small cell lung cancer. Lab Investig 2014; 94: 107-116. doi: 10.1038/labinvest.2013.130

[13] COOPER WA, TRAN T, VILAIN RE, MADORE J, SELINGER CI et al. PD-L1 expression is a favorable prognostic factor in early stage non-small cell carcinoma. Lung Cancer 2015; 89: 181-188. doi: 10.1016/j.lungcan.2015.05.007

[14] ZHANG Y, WANG L, LI Y, PAN Y1, WANG R et al. Protein expression of programmed death 1 ligand 1 and ligand 2 independently predict poor prognosis in surgically resected lung adenocarcinoma. Onco Targets Ther 2014; 7: 567-573. doi: 10.2147/OTT.S59959

[15] WANG A, WANG HY, LIU Y, ZHAO MC, ZHANG HJ et al. The prognostic value of PD-L1 expression for non-small cell lung cancer patients: A meta-analysis. Eur J Surg Oncol 2015; 41: 450-456. doi: 10.1016/j.ejso.2015.01.020

[16] ZHOU ZJ, ZHAN P, SONG Y. PD-L1 over-expression and survival in patients with non-small cell lung cancer: a meta-analysis. Transl Lung Cancer Res 2015; 4: 203-208. doi: 10.3978/j.issn.2218-6751.2015.03.02

[17] SCHMIDT LH, KÜMMEL A, GÖRLICH D, MOHR M, BRÖCKLING S et al. PD-1 and PD-L1 Expression in NSCLC Indicate a Favorable Prognosis in Defined Subgroups. PLoS One. 2015; 10: e0136023. doi: 10.1371/journal.pone.0136023

[18] SORENSEN S, ZHOU W, DOLLED-FILHART M, GEORGSEN JB, WANG $Z$ et al. PD-L1 expression and survival among patients with advanced non-small cell lung cancer treated with chemotherapy. Transl Oncol 2016; 9: 64-69. doi: 10.1016/j.tranon.2016.01.003

[19] ADAM J, BOROS A, LACAS B, LACROIX L, PIGNON JP et al. Prognostic value of PDL1 expression in stage III NonSmall Cell Lung Cancer (NSCLC) treated by chemo-radiotherapy (CRT). Eur J Cancer 2015; 51 (Suppl 6): S604. doi: 10.1016/S0959-8049(16)31668-9

[20] TOKITO T, AZUMA K, KAWAHARA A, ISHII H, YAMADA K et al. Predictive relevance of PD-L1 expression combined with CD8+ TIL density in stage III non-small cell lung cancer patients receiving concurrent chemoradiotherapy. Eur J Cancer 2016; 55: 7-14. doi: 10.1016/j.ejca.2015.11.020

[21] FORMENTI SC, DEMARIA S. Combining radiotherapy and cancer immunotherapy: a paradigm shift. J Natl Cancer Inst 2013; 105: 256-265. doi: 10.1093/jnci/djs629 
[22] TANG C, WANG X, SOH H, SEYEDIN S, CORTEZ MA et al. Combining radiation and immunotherapy: a new systemic therapy for solid tumors? Cancer Immunol Res 2014; 2: 831-838. doi: 10.1158/2326-6066.CIR-14-0069

[23] MELCHER A, GOUGH M, TODRYK S, VILE R. Apoptosis or necrosis for tumor immunotherapy: what's in a name? J Mol Med (Berl). 1999; 77: 824-833.

[24] KOTERA Y, SHIMIZU K, MULÉ JJ. Comparative analysis of necrotic and apoptotic tumor cells as a source of antigen(s) in dendritic cell-based immunization. Cancer Res 2001; 61: 8105-8109.

[25] DEMARIA S, BHARDWAJ N, MCBRIDE WH, FORMENTI SC. Combining radiotherapy and immunotherapy: a revived partnership. Int J Radiat Oncol Biol Phys 2005; 63: 655-666. doi: 10.1016/j.ijrobp.2005.06.032

[26] GOLDEN EB, FRANCES D, PELLICCIOTTA I, DEMARIA $S$, HELEN BARCELLOS-HOFF $M$ et al. Radiation fosters dose-dependent and chemotherapy-induced immunogenic cell death. Oncoimmunology 2014; 3: e28518. doi: 10.4161/ onci.28518

[27] KIM YH, GRATZINGER D, HARRISON C, BRODY JD, CZERWINSKI DK et al. In situ vaccination against mycosis fungoides by intratumoral injection of a TLR9 agonist combined with radiation: a phase $1 / 2$ study. Blood 2012; 119: 355-363. doi: 10.1182/blood-2011-05-355222

[28] BRODY JD, AI WZ, CZERWINSKI DK, TORCHIA JA, LEVY $M$ et al. In situ vaccination with a TLR9 agonist induces systemic lymphoma regression: a phase I/II study. J Clin Oncol 2010; 28: 4324-4332. doi: 10.1200/JCO.2010.28.9793

[29] POSTOW MA, CALLAHAN MK, BARKER CA, YAMADA Y, YUAN J et al. Immunologic correlates of the abscopal effect in a patient with melanoma. N Engl J Med 2012; 366: 925-931. doi: 10.1056/NEJMoa1112824

[30] GOLDEN EB, DEMARIA S, SCHIFF PB, CHACHOUA A, FORMENTI SC. An abscopal response to radiation and ipilimumab in a patient with metastatic non-small cell lung cancer. Cancer Immunol Res 2013; 1: 365-372. doi: 10.1158/2326-6066.CIR-13-0115
[31] TENG F, KONG L, MENG X, YANG J, YU J. Radiotherapy combined with immune checkpoint blockade immunotherapy: Achievements and challenges. Cancer Letters 2015; 365: 23-29. doi: 10.1016/j.canlet.2015.05.012

[32] SZNOL M, CHEN L. Antagonist antibodies to PD-1 and B7-H1 (PD-L1) in the treatment of advanced human cancer. Clin Cancer Res 2013; 19: 1021-1034. doi: 10.1158/10780432.CCR-12-2063

[33] Demaria S1, Golden EB2, Formenti SC. Role of Local Radiation Therapy in Cancer Immunotherapy. JAMA Oncol 2015; 1: 1325-1332. doi: 10.1001/jamaoncol.2015.2756

[34] LIM SH, HONG M, AHN S, CHOI YL, KIM KM et al. Changes in tumour expression of programmed death-ligand 1 after neoadjuvant concurrent chemoradiotherapy in patients with squamous oesophageal cancer. Eur J Cancer 2016; 52: 1-9. doi: 10.1016/j.ejca.2015.09.019

[35] DENG L, LIANG H, BURNETTE B, BECKETT M, DARGA $T$ et al. Irradiation and anti-PD-L1 treatment synergistically promote antitumor immunity in mice. J Clin Invest 2014; 124: 687-695. doi: 10.1172/JCI67313

[36] PETRELLI NJ, WINER EP, BRAHMER J, DUBEY S, SMITH $S$ et al. Clinical cancer advances 2009: major research acvances in cancer treatment, prevention, and screening-a report from the American Society of Clinical Oncology. J Clin Oncol 2009; 27: 6052-6069. doi: 10.1200/JCO.2009.26.6171

[37] TOPALIAN SL, HODI FS, BRAHMER JR, GETTINGER SN, SMITH DC et al. Safety, activity, and immune correlates of anti-PD-1 antibody in cancer. N Engl J Med 2012; 366: 2443-2454. doi: 10.1056/NEJMoa1200690

[38] COOPER WA, TRAN T, VILAIN RE, MADORE J, SELINGER CI et al. PD-L1 expression is a favorable prognostic factor in early stage non-small cell carcinoma. Lung Cancer 2015; 89: 181-188. doi: 10.1016/j.lungcan.2015.05.007

[39] ILIE M, LONG-MIRA E, BENCE C, BUTORI C, LASSALLE $S$ et al. Comparative study of the PD-L1 status between surgically resected specimens and matched biopsies of NSCLC patients reveal major discordances: a potential issue for anti-PD-L1 therapeutic strategies. Ann Oncol 2016; 27: 147-153. doi: 10.1093/annonc/mdv489 